Article

\title{
Design of Gelatin Pouches for the Preservation of Flaxseed Oil during Storage
}

\author{
Hela Kchaou ${ }^{1, *}$, Mourad Jridi ${ }^{1,2}$, Moncef Nasri ${ }^{1}$ and Frédéric Debeaufort ${ }^{3,4}$ \\ 1 Laboratory of Enzyme Engineering and Microbiology, National School of Engineering of Sfax, University \\ of Sfax, P.O. Box 1173, Sfax 3038, Tunisia; jridimourad@gmail.com (M.J.); mon_nasri@yahoo.fr (M.N.) \\ 2 Higher Institute of Biotechnology of Beja, University of Jendouba, Avenue Habib Bourguiba Beja 9000, \\ Beja BP: 382, Tunisia \\ 3 AgroSup Dijon, University Bourgogne Franche-Comté, UMR PAM A 02.102, 1 Esplanade Erasme, \\ 21000 Dijon, France; frederic.debeaufort@u-bourgogne.fr \\ 4 IUT-Dijon-Auxerre, BioEngineering Dpt., 7 blvd Docteur Petitjean, CEDEX, 20178 Dijon, France \\ * Correspondence: hela.kchaou.enis@gmail.com
}

Received: 10 December 2019; Accepted: 5 February 2020; Published: 7 February 2020

\begin{abstract}
Flaxseed oil (FO) is composed mainly of polyunsaturated fatty acids that are very sensitive to oxidation induced by oxygen, temperature, and light. To overcome this problem, gelatin-based films containing glucose are crosslinked via the Maillard reaction (MR) at $120^{\circ} \mathrm{C}$ and used for the conception of pouches in which the FO was packaged. The prepared pouches, as well as the oil alone, are incubated at $50{ }^{\circ} \mathrm{C}$ for 21 days. The results show that the peroxide index of the oil stored in the gelatin-based pouches is almost stable and decreases on the 21st day. The specific extinction coefficients prove a more pronounced degradation of the non-package oil (control). In addition, the results of thiobarbituric acid reactive substances (TBARs) test reveal higher values in the control, with a tendency to continuously increase up until the 21st day. However, the oil stored in the pouches reveals less TBARs content, decreasing with oxidation time. The non-heated glucose-supplemented pouches showed the best results, suggesting a moderate and gradual development of the MR at $50{ }^{\circ} \mathrm{C}$. The application of pouches based on gelatin films seems to be an effective and interesting tool for protecting FO against lipid oxidation, acting as perfectly biodegradable and sustainable containers for small doses.
\end{abstract}

Keywords: gelatin pouches; Maillard reaction; flaxseed oil; lipid oxidation

\section{Introduction}

Flaxseed oil (FO) is rich in polyunsaturated fatty acids (PUFA), namely $\alpha$-linolenic acid (18:3 $n-3)$, which is especially important for human health [1]. In addition, this vegetable oil is known to have therapeutic potential as an anti-inflammatory and anti-hypertensive agent, as well as possessing high bioavailability and solubility of lipophilic compounds for efficient drug delivery [2,3]. However, flaxseed oil is extremely susceptible to oxidative rancidity because of the presence of double bonds in the main chain of the unsaturated fatty acid molecules, which represent more than $75 \%$ of the oil [4]. These properties lead to a major problem during storage and represent a limitation for application in functional foods [3].

Indeed, the process of lipid oxidation is initiated by light radiation and atmospheric oxygen and is maintained through the generation of free radicals during the consequent chain reaction [5], where hydroperoxides are formed as a result. As they are unstable, they decompose relatively quickly into aldehydes, ketones, alcohols, acids, esters, or hydrocarbons [6]. These latter, secondary oxidative products induce the characteristic off-flavor of oxidized oils, leading therefore to a loss in nutritional 
and organoleptic properties. Moreover, during the oxidation process, toxic compounds (hydroperoxyand hydroxy-alkenals) are formed [7]. Thus, the prevention or the retardation of the lipid oxidation process is required. Among the solutions, the addition of some synthetic antioxidants such as butylated hydroxyanisole (BHA) and butylated hydroxytoluene (BHT) to oils and food products is commonly used [8]. Despite their efficiency in avoiding the oxidative rancidity of fatty substances, their low cost, and availability, synthetic antioxidants have been suspected to generate negative health effects, presenting toxic and carcinogenic risks $[9,10]$. To overcome this problem, several research studies are currently being conducted in order to discover new natural antioxidant molecules as alternatives to synthetic antioxidants. As natural antioxidants, plant extracts (from rosemary, oregano olive waste cake extract, clove, cinnamon, etc.) including those from the seeds of oil plants and vegetable oils, as well as fruit extracts, are becoming more and more popular nowadays due to their beneficial health effects as compared to synthetic antioxidants [11]. In this context, Śpitalniak-Bajerska et al. [11] investigated the antioxidant efficacy of apple pomace comprising polyphenolic compounds as a natural antioxidant for the stability of flaxseed oil in anaerobic conditions. Recently, Varas Condori et al. [12] reported that the addition of a lycopene-rich tomato extract increased the flaxseed oil shelf-life by acting as a scavenger that slowed the oxidation mechanism. Furthermore, oil encapsulation, which consists of surrounding the oil droplets in a polymer matrix, works as a protecting wall against environmental conditions (i.e., protecting against temperature, light, oxidizing agents, etc.), representing another potential solution to delay the oxidative rancidity process in highly unsaturated oils $[4,13]$.

The use of active packaging to avoid or retard the oxidation process can be an alternative to oil encapsulation with a polymer matrix. In this context, recent works have reported the effectiveness of gelatin-based films in the retardation of oils oxidation. Sai-Ut et al. [6] noted that the incorporation of longan seed extract or BHT in gelatin films retards lipid oxidation in soybean oil. In another recent study, Nilsuwan et al. [14] investigated the use of fish gelatin monolayer and bilayer films containing epigallocatechin gallate as pouches for the extended storage of chicken skin oil. These authors displayed a delay and a reduction of the oxidation reaction rate.

In a previous study, Kchaou et al. [15] reported that the development of fish gelatin films crosslinked by the Maillard reaction showed interesting antioxidant potential. This was assessed in vitro via various tests by investigating the free radical scavenging activity using DPPH (2.2 Diphenyl 1 picrylhydrazyl) and ABTS (2,2'-azino-bis(3ethylbenz-thiazoline-6-sulfonic acid) radicals, elucidating the reducing power, $\beta$-carotene bleaching inhibition, and the linoleic acid oxidation inhibition. In this context, the results reveal that glucose-gelatin films heated at high temperatures show antioxidant potential with different modes of actions (e.g., electron transfer and hydrogen atom donation). Thus, the aim of the present work is to investigate thermally modified gelatin-based films to provide antioxidant capacity for a pre-dosed use as active pouches in order to preserve flaxseed oil against lipid oxidation.

\section{Material and Methods}

\subsection{Materials}

Commercial fish gelatin type A (Rousselot $200 \mathrm{FG}, 200$ degree bloom, $4 \mathrm{mPa} \cdot \mathrm{s}$ viscosity at $45^{\circ} \mathrm{C}$ for a concentration of $6.67 \%$ in water at $\mathrm{pH}=5.4$, Rousselot, Isle sur la Sorgue, France) was employed as a filmogenic biopolymer for film preparation. Anhydrous glycerol ( $98 \%$ purity) was purchased from Fluka (Fluka Chemical-Sigma Aldrich, Taufkirchen, Germany). D(+) anhydrous-glucose (LOBA Chemie, Mumbay, India) was used as the reducing sugar to initiate the Maillard reaction in fish gelatin-based films. Organic virgin flaxseed oil (cold pressure extracted) was purchased from Huilerie de Lapalisse (Lapalisse, France). Moreover, other reagents (purchased from Sigma Aldrich, Saint Quentin-Fallavier, France) were used for chemical tests, including isooctane, 2-propanol, methanol, 1-butanol, acetone, hydrochloric acid $(\mathrm{HCl})$, thiobarbituric acid (TBA), trichloroacetic acid, barium chloride $\left(\mathrm{BaCl}_{2}\right)$, iron (II) sulfate $\left(\mathrm{FeSO}_{4}\right)$, ammonium thiocyanate, cupric acetate, pyridine, cumene hydroperoxide, 1,1,3,3-tetraethoxypropane (malonaldehydebis(dimethyl acetal)), and oleic acid. 


\subsection{Film Preparation}

A film-forming solution was prepared by dissolving $4 \%(w / v)$ fish gelatin (FG) in distilled water at $60{ }^{\circ} \mathrm{C}$. Then, glycerol, as a plasticizer, was added to the solution at a concentration of $15 \%(w / w$ dry gelatin matter), equivalent to $0.6 \%(w / v)$ and the mixture was maintained under stirring for $30 \mathrm{~min}$. Glucose (Glc) was added to the film-forming solution at a $0.5 / 1.0$ glucose/lysine molar ratio equivalent to $0.088 \%(w / v)$, as per a previous study [16].

The same volume of the film-forming solution $(25 \mathrm{~mL})$, with or without glucose, was poured into a 12-cm square polystyrene Petri dish $\left(144 \mathrm{~cm}^{2}\right.$ of surface area) and then dried in a ventilated climatic chamber (KBF 240 Binder, ODIL, France) at $25^{\circ} \mathrm{C}$ at $50 \%$ relative humidity (RH) for $24 \mathrm{~h}$. The dried films were manually peeled off from the surface and half of them (with or without glucose) were heated in an oven at $120^{\circ} \mathrm{C}$ for $24 \mathrm{~h}$. Thus, the heat treatment of glucose-gelatin films (FG-Glc $25^{\circ} \mathrm{C}$ ) induced the Maillard reaction and led to the production of Maillard crosslinked films, referred to as FG-Glc $120^{\circ} \mathrm{C}$ (gelatin-glucose films heated at $120^{\circ} \mathrm{C}$ ). Glucose-free gelatin films were prepared and considered as controls, referred to as FG (gelatin films). All prepared films were then equilibrated at $25{ }^{\circ} \mathrm{C}$ and $50 \% \mathrm{RH}$ for $48 \mathrm{~h}$ before being used for flaxseed oil packaging.

\subsection{Oxygen Transfer Through the Films}

The oxygen transfer was assessed using a manometric method with a commercial permeability testing apparatus (Brugger, Type GDP-C, Brugger Feinmechanik GmbH, Munich, Germany). The film sample of the $144 \mathrm{~cm}^{2}$ surface area was placed between the top and bottom part of the permeation cell. The exposed area to the transfer of oxygen was $95.1 \mathrm{~cm}^{2}$. Prior to each test, the bottom part of the permeation cell was out-gassed under a primary vacuum $(<2 \mathrm{hPa})$. During testing, the top part was continuously flushed with the tested gas $\left(\mathrm{O}_{2}\right)$. In the bottom chamber, the pressure increase was monitored over time. The permeation transfer rate was calculated from the steady state and then expressed in $\mathrm{cm}^{3} / \mathrm{m}^{2}$.d. Temperature was maintained $\left(25 \pm 0.5^{\circ} \mathrm{C}\right)$ using a water bath (Julabo F32). The oxygen permeation measurements were conducted at $0 \%$ relative humidity because the oil is considered as a dry product.

\subsection{Packaging of Flaxseed Oil (FO) in Gelatin Pouches}

Gelatin-based films either containing or not containing glucose, heated or not at $120{ }^{\circ} \mathrm{C}$ (FG $25^{\circ} \mathrm{C}$, FG $120^{\circ} \mathrm{C}$, FG-Glc $25^{\circ} \mathrm{C}$, and FG-Glc $120^{\circ} \mathrm{C}$ ), were used for the preparation of the pouches. To this end, aforementioned films were first folded in half and then thermally welded on 2 sides (the sealing temperature was about $120-130{ }^{\circ} \mathrm{C}$ ) in order to form pouches. This was done using a CONSERVAIR ${ }^{\circledR}$ machine (heat seal machine). Then, FO $(10 \mathrm{~mL})$ was transferred into the pouches which were subsequently welded thermally on the fourth side. Furthermore, two controls were prepared. The positive control contained FO in a closed bottle, while the negative control contained FO in an open bottle. The prepared pouches, as well as the positive and negative controls, were incubated in darkness at $50^{\circ} \mathrm{C}$ for 21 days as an accelerated test (Figure 1). Oil samples were periodically sampled in order to monitor the FO thermo-oxidation kinetics.

\subsection{Quality Changes of FO Packaged in Gelatin Pouches}

\subsubsection{Peroxide Value (PV)}

The peroxide value (PV) was determined according to the method of Uluata et al. [17]. An oil sample of $0.2 \mathrm{~g}$ was added to a mixed solvent of $1.6 \mathrm{~mL}$ of isooctane/2-propanol (3:1 $\mathrm{v} / \mathrm{v})$ and then vigorously vortexed (10 s, 3 times). Then, $0.2 \mathrm{~mL}$ of the upper extract was carefully removed and blended with a mixed solvent of $2.8 \mathrm{~mL}$ of methanol/1-butanol mixture $(2: 1, v / v)$. Subsequently, $15 \mu \mathrm{L}$ of $\mathrm{Fe}^{2+}$ solution (freshly prepared from the supernatant of a mixture of equal volume of $0.132 \mathrm{M}$

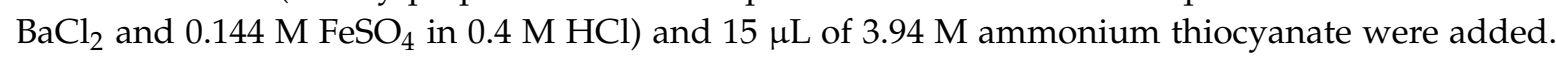
The final mixture $(3 \mathrm{~mL})$ was vortexed and kept at room temperature in the dark for $20 \mathrm{~min}$. The 
absorbance of the mixture was measured at $510 \mathrm{~nm}$ with a UV spectrophotometer (Model V-530, Jasco, Nantes, France). Peroxide values were calculated with a standard curve of cumenehydroperoxide at concentrations ranging from 0 to $0.2 \mathrm{mg} / 3 \mathrm{~mL}$. The results were expressed in terms of mmoles of cumene hydroperoxide equivalent per $\mathrm{g}$ of oil.

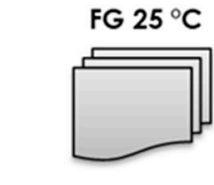

FG $25^{\circ} \mathrm{C}$ Glucose-free gelatin films non heated

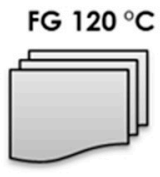

FG $120^{\circ} \mathrm{C}$

Glucose-free gelatin films heated at $120^{\circ} \mathrm{C}$
FG-GIC $25^{\circ} \mathrm{C}$

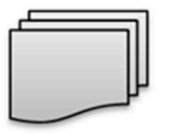

FG-Glc $25^{\circ} \mathrm{C}$

Gelatin-glucose films

non heated
FG-GlC $120^{\circ} \mathrm{C}$

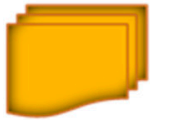

FG-Glc $120^{\circ} \mathrm{C}$

Gelatin-glucose films heated at $120^{\circ} \mathrm{C}$

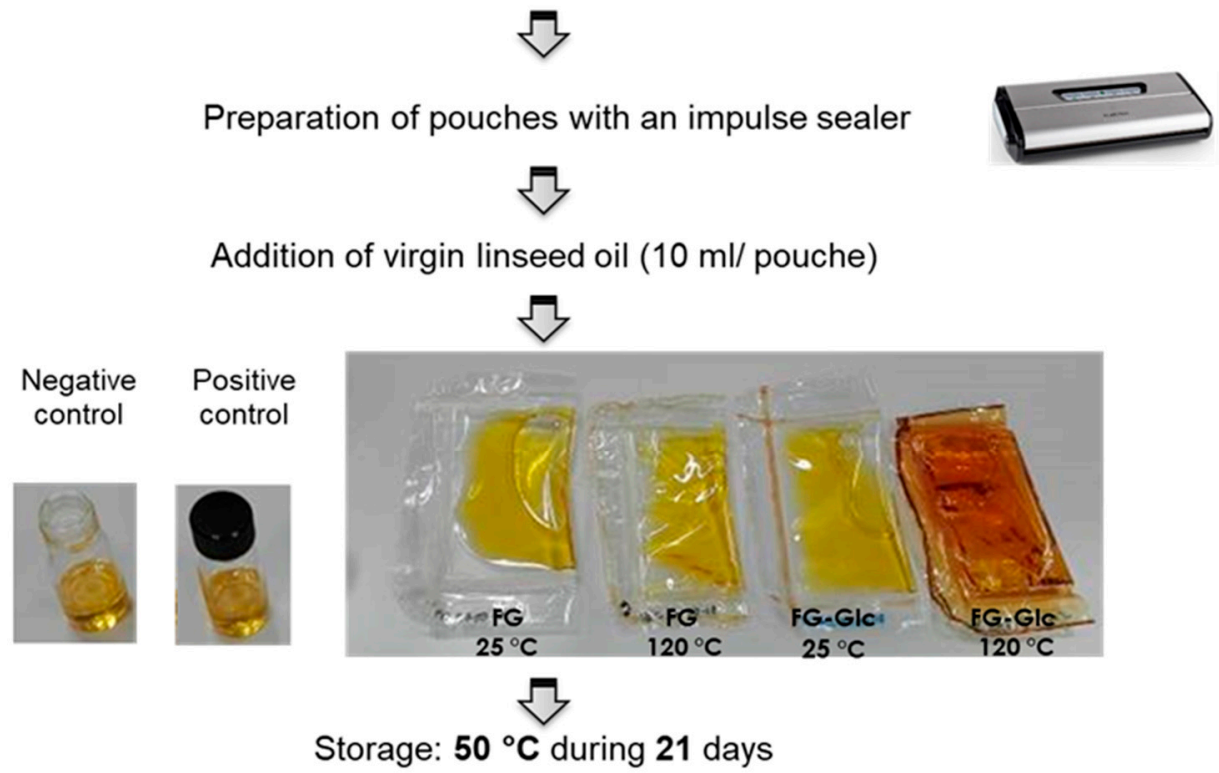

Thermo-oxidation

Figure 1. Packaging of flaxseed oil in glucose-free gelatin and gelatin-glucose pouches. FG: Fish gelatin film. FG-Glc: Glucose-Fish gelatin film.

\subsubsection{Concentration of Thiobarbituric Acid Reactive Substances (TBARs)}

Thiobarbituricacid reactive substance (TBARs) values were determined with the modified method of Qiu et al. [18]. A TBA reagent was prepared by dissolving $0.375 \mathrm{~g}$ of TBA, $1.76 \mathrm{~mL}$ of $12 \mathrm{M} \mathrm{HCl}$ and $15 \mathrm{~g}$ of trichloroacetic acid into $82.9 \mathrm{~mL}$ of distilled water. An oil sample of $0.2 \mathrm{~mL}$ was incorporated into the $3.8 \mathrm{~mL}$ TBA reagent in a test tube with slight shaking and then placed in a boiling water bath for $20 \mathrm{~min}$. The mixture was centrifuged at $3000 \times \mathrm{g}$ for $15 \mathrm{~min}$ after cooling down in an ice water bath and then measured at $532 \mathrm{~nm}$ with a UV spectrophotometer. A standard curve was prepared using 1,1,3,3-tetraethoxypropane (malonaldehydebis(dimethyl acetal)) in the TBA reagent at concentrations ranging from 0 to $0.1 \mathrm{~mL} / 2 \mathrm{~mL}$. The results of TBARs concentrations were expressed as the malonaldehyde equivalent in $\mathrm{mL}$ per $\mathrm{g}$ of oil.

\subsection{3. $\mathrm{K}_{270}$ Extinction Coefficient}

The oil samples were diluted in acetone and then, after homogenization, the optical density was measured at $270 \mathrm{~nm}$ using a spectrophotometer (SAFAS UVmc, Monaco city, Monaco) in order to assess the development of secondary oxidation products [19]. Pure acetone was used as a reference 
here. Indeed, the specific extinction coefficient was used to characterize the degree and the stage of oxidation of oil. During the oxidation, the hydroperoxides, the primary oxidation products, are converted into various secondary products, including volatile and non-volatile off-flavor products, namely, esterified aldehydes, which absorb in the UV range of about $270 \mathrm{~nm}$ [19].

\subsubsection{Free Fatty Acid Content (FFA)}

The free fatty acid content (FFA), used as an index of hydrolysis, was determined according to the method of Takeungwongtrakul et al. [20]. An oil sample $(0.1 \mathrm{~g})$ was added with $5 \mathrm{~mL}$ of isooctane and swirled vigorously to dissolve the sample. The mixture was then added with $1 \mathrm{~mL}$ of a $5 \%(w / v)$ cupric acetate-pyridine reagent, freshly prepared by dissolving $5 \mathrm{~g}$ of the reagent grade cupric acetate in $100 \mathrm{~mL}$ of water, filtering, and then adjusting the $\mathrm{pH}$ to $6.0-6.2$ using pyridine. The mixture was shaken vigorously for $90 \mathrm{~s}$ using a vortex and allowed to stand for $20 \mathrm{~s}$. The upper layer was subjected to absorbance measurement at $715 \mathrm{~nm}$. A standard curve was prepared using oleic acid in isooctane at concentrations ranging from 0 to $50 \mu \mathrm{mol} / 5 \mathrm{~mL}$. Free fatty acid (FFA) content was then expressed as $\mathrm{g}$ of oleic acid per $100 \mathrm{~g}$ of oil (goleic acid $\left./ 100 \mathrm{~g}_{\text {oil }}\right)$.

\subsubsection{Intrinsic Viscosity of FO}

The intrinsic viscosity of flaxseed oil, before and after oxidation, was assisted using an NMR apparatus (Bruker Minispec mq20, Palaiseau, France). This technique allows the measurement of the oil relaxation time $\left(\mathrm{T}_{2}\right)$. The analysis was carried out using a gain of around $65 \mathrm{~dB}$, with 16 scans, a recycle delay of $20 \mathrm{~s}$, and a frequency of $20 \mathrm{MHz}$. Then, $\mathrm{T}_{2}$ was directly related to the local viscosity according the Boltzman and Stokes-Einstein laws.

\subsection{Changes of Gelatin Pouches before and after Application}

\subsubsection{Color}

A CIE colorimeter (Chroma Meter CR-400; Konica Minolta, Roissy, France) was used in order to assess the color changes of flaxseed oil and gelatin pouches before and after application. A white standard color plate $\left(\mathrm{L}_{0}=97.5, \mathrm{a}_{0}=-0.1\right.$ and $\left.\mathrm{b}_{0}=2.3\right)$ was used as a background for the color measurements. The color of the gelatin pouches and that of the flaxseed oil were expressed as $\mathrm{L}$ (lightness/brightness), a (redness/greenness), and b (yellowness/blueness) values.

\subsubsection{Light Transmission}

Gelatin pouches samples $(1 \times 3 \mathrm{~cm})$ were placed in the test cell of a UV-visible spectrophotometer (SAFAS UVmc, Monaco city, Monaco). An empty test cell was used as a reference. The UV-vis absorption spectra was recorded in the wavelength range of 200 to $800 \mathrm{~nm}$.

\subsubsection{Differential Scanning Calorimetry (DSC)}

The thermal properties of the gelatin pouches were studied using a differential scanning calorimeter (DSC Q20, TA Instruments, Guyancourt, France). Pouches ( $5 \mathrm{mg}$ ) were placed into aluminum pans, sealed, and subjected to a double heating-cooling cycle from $-50{ }^{\circ} \mathrm{C}$ to $150{ }^{\circ} \mathrm{C}$ at a rate of $10^{\circ} \mathrm{C} / \mathrm{min}$. An empty aluminum pan was used as a reference. Nitrogen was used as the purge gas at a flow rate of $25 \mathrm{~mL} / \mathrm{min}$. The glass transition temperature (Tg) for each sample was then determined from the mid-point of the second heating cycle using the TA Universal Analysis 2000 software (version $4.5 \mathrm{~A}$, TA instruments, Guyancourt, France).

\subsection{Statistical Analysis}

Statistical analyses were performed with SPSS version 17.0, professional edition, using ANOVA analysis at a $p$-value $<0.05$. Duncan's multiple range test $(p$-value $<0.05)$ was used to detect differences among the mean values of all the analyzed parameters. 


\section{Results and Discussion}

\subsection{Quality Changes of Flaxseed Oil Packaged in Gelatin Pouches}

\subsubsection{Peroxide Value (PV)}

The oxidation of flaxseed oil was assessed firstly by the measurement of the peroxide value. This index is used for the determination of the concentration of hydroperoxides formed at the initial stage of lipid oxidation, which are unstable and easily spontaneously decomposed into secondary oxidation products [21,22]. The results in Figure 2 display the variation of the peroxide value (PV) as a function of storage time. The peroxide index of the oil stored in the gelatin-based pouches increased slightly on the 4 th day and then was maintained as almost stable until the 15 th day. During the early stages of storage, the lipid oxidation was propagated by consuming oxygen present in the headspace of the pouch [23]. Among all the formulations, FO packaged in non-heated gelatin-glucose (FG-Glc $25^{\circ} \mathrm{C}$ ) pouches exhibited the best oxidation stability, as it showed the lower peroxide values during the storage period of 15 days. Indeed, FG-Glc $25{ }^{\circ} \mathrm{C}$ pouches contain glucose and were exposed to a moderate heat treatment $\left(50^{\circ} \mathrm{C}, 15\right.$ days) during the storage test, which induced the development of Maillard reaction and the possibility of the release of antioxidants (MR products). Therefore, this fact may explain the higher stability of FO packaged in FG-Glc $25^{\circ} \mathrm{C}$ pouches as compared to the other pouches formulations. At the 21st day, a significant decrease in the PV to $0.48,0.83,0.87,0.72$ mMoles cumene hydroperoxide equivalent/g of oil was noted for FO packaged in FG $25^{\circ} \mathrm{C}$, FG $120^{\circ} \mathrm{C}$, FG-Glc $25^{\circ} \mathrm{C}$ and FG-Glc $120^{\circ} \mathrm{C}$, respectively. This decrease in the PV suggest the decomposition of peroxides to secondary oxidation products. However, for the positive and negative controls, peroxide values increased significantly as a function of storage time and reached 6.75 and 9.40 mMoles cumene hydroperoxide equivalent/g of oil at the 21st day, respectively. This increase in PV evidences the continuous progression of the oil oxidation process until the 21st day. Indeed, lipid radicals react with oxygen to form peroxyl radicals, which act as the chain carriers of the rapid progressing reaction by attacking new lipid molecules [21]. These results are in accordance with those of Nilsuwan et al. [14], who reported that chicken skin oil packaged in the pouches based on fish gelatin and those containing epigallocatechin gallate showed a lower peroxide value after 30 days of storage at $25-28{ }^{\circ} \mathrm{C}$, in comparison with that packaged in low-density polyethylene pouches (which were used as a control).

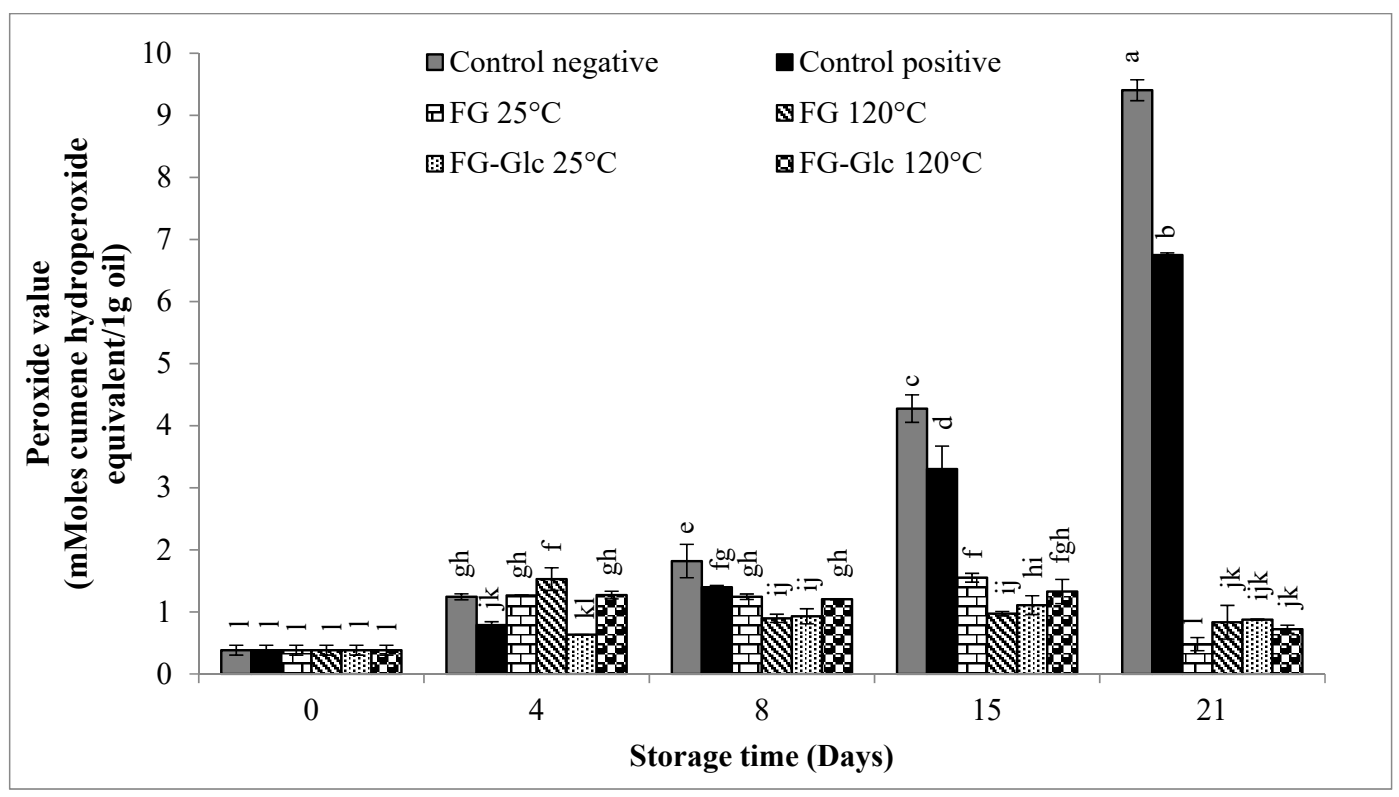

Figure 2. Peroxide value of flaxseed oil packaged or not in different gelatin pouches as a function of storage time. Means with different superscripts $(a-1)$ indicate a significant difference $(p<0.05)$. 


\subsubsection{Thiobarbituric Acid Reactive substances (TBARs)}

The development of secondary oxidation products in FO was monitored by the measurement of the thiobarbituric acid reactive substances (Figure 3). Indeed, TBARs have been used to measure the concentration of relatively polar secondary lipid oxidation products, especially aldehydes, including malondialdehyde (MDA) [24]. The results reveal that the oil stored in the pouches, especially in gelatin-glucose ones, display less TBARs content, decreasing with oxidation time from 10.28 and $13.69 \mathrm{~mL}$ equivalent MDA/g of oil at the 4 th day to 5.56 and $7.27 \mathrm{~mL}$ equivalent MDA/g of oil at the 21st day, respectively, for the FG-Glc $25^{\circ} \mathrm{C}$ and FG-Glc $120^{\circ} \mathrm{C}$ pouches. The protective effect seen in the gelatin-glucose pouches for flaxseed oil oxidation could be explained by their antioxidant potential, which is in agreement with our previous study which revealed the in vitro lipid peroxidation inhibition ability of Maillard reaction-treated gelatin-glucose films during linoleic acid storage at $45^{\circ} \mathrm{C}$ [15]. However, higher TBARs values have been obtained for the controls, with a tendency to continuously increase until the 21st day to reach 25.48 and $34.59 \mathrm{~mL}$ equivalent MDA/g of oil, respectively, for the positive and negative controls. The continuous increase of TBARs content could be due to the availability of oxygen in FO stored in the open bottle (negative control) and the lower oxygen barrier property of the closed bottle (positive control) as compared to gelatin pouches. These findings indicate the protective effect of gelatin pouches in retarding the oxidation of flaxseed oil.

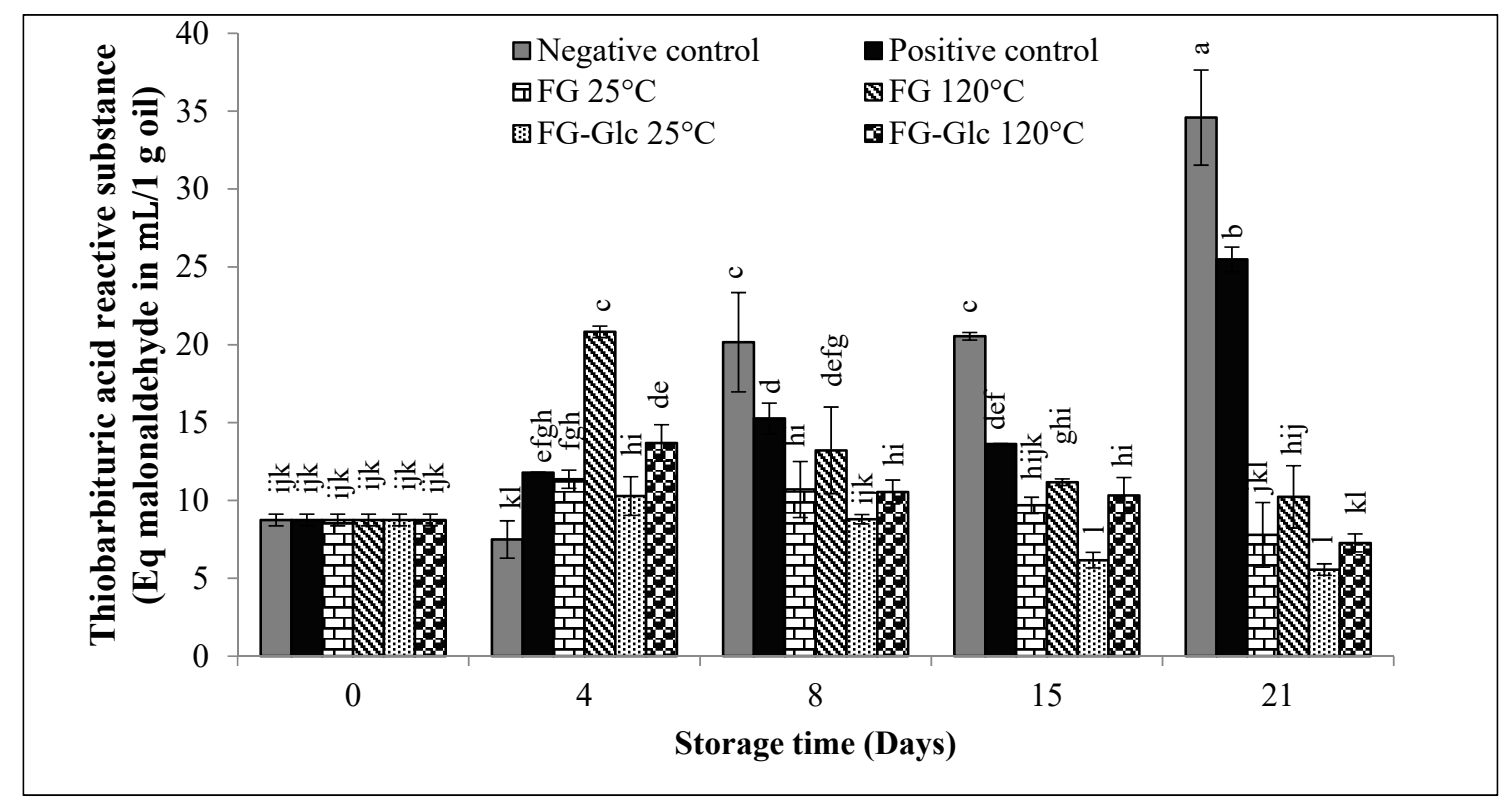

Figure 3. Thiobarbituric acid reactive substances of flaxseed oil packaged or not in different gelatin pouches as a function of storage time. Means with different superscripts (a-l) indicate a significant difference $(p<0.05)$.

\subsection{3. $\mathrm{K}_{270}$ Extinction Coefficient}

Furthermore, the absorbance at $270 \mathrm{~nm}$ has been determined for FO packaged or not in gelatin pouches in order to confirm the development of secondary oxidation products. Indeed, the greater the extinction at $270 \mathrm{~nm}$, the greater the richness of secondary oxidation products in the oil, which reflects its poor preservation ability [25]. As can be seen in Figure 4, both the positive and negative controls displayed higher absorbance values compared to that of oil packaged in gelatin pouches. In addition, absorbance values increased significantly as a function of storage time. This increase in the $\mathrm{K}_{270 \mathrm{~nm}}$ values reveals the continuous propagation of the lipid oxidation reaction to the development of secondary products in the control FO, as demonstrated previously by the TBARs test. 


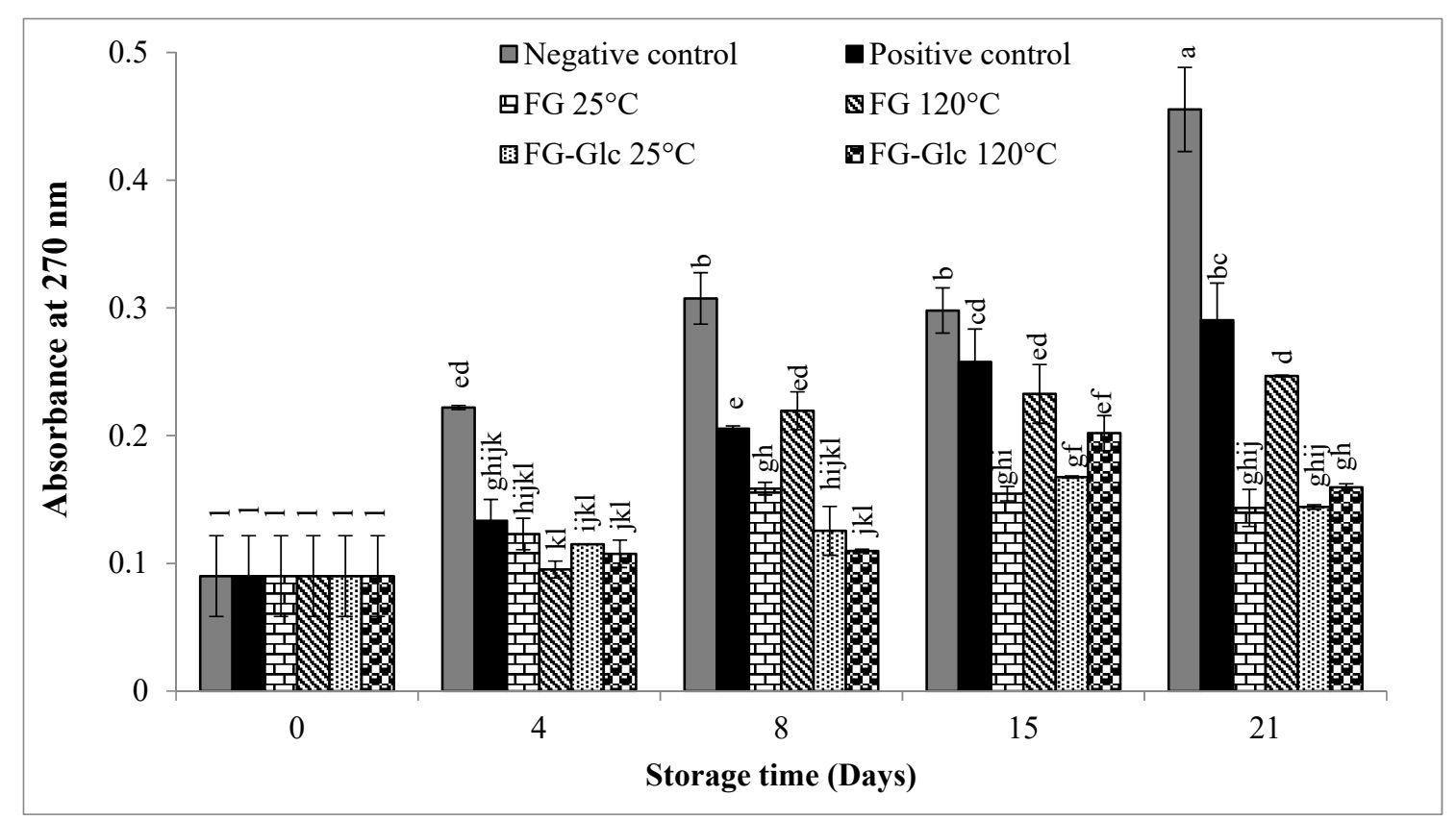

Figure 4. Absorbance at $270 \mathrm{~nm}$ of flaxseed oil packaged or not in different gelatin pouches as a function of storage time. Means with different superscripts $(a-1)$ indicate a significant difference $(p<0.05)$.

\subsubsection{Free Fatty Acid (FFA) Content}

The variation of free fatty acid content of FO packaged in gelatin pouches as a function of storage time was investigated and results are presented in Figure 5. FO packaged in gelatin pouches revealed a lower free fatty acid content compared to the control oils, especially at the third week of storage. Among the different formulations, FO packaged in unheated FG and FG-Glc pouches displayed a lower FFA content $(p<0.05)$ and the values found on the 21 st day were 0.260 and $0.310 \mathrm{~g}$ oleic acid/100 $\mathrm{g}$ of oil, respectively. Indeed, the release of free fatty acids reveals the presence of hydrolysis, which seems to be favored by heat-treated films. However, on the 21st day, both the positive and negative controls displayed the highest hydrolysis rate of polyunsaturated fatty acids and the obtained values were 0.85 and $1.26 \mathrm{~g}$ oleic acid/100 $\mathrm{g}$ of oil, respectively. Indeed, the increase in free fatty acid content in uncovered flaxseed oils (positive and negative controls) at the end of the storage period (21st day) can be explained by the oxidation process, which is favored by temperature $\left(50{ }^{\circ} \mathrm{C}\right)$ and the presence of oxygen. Furthermore, as the lipid oxidation process was favored and reached a maximum in the 21st day (as proven by the peroxide index and TBARs results), the hydrolysis rate of polyunsaturated fatty acids will be bigger, and the free fatty acid content will be more important. The hydrolysis of glycerol-fatty acid esters occurs normally in lipids and is catalyzed by lipases and phospholipases [26]. Generally, lipids can undergo hydrolysis in the presence of moisture and heat [24]. According to Takeungwongtrakul et al. [20], released free fatty acids are likely prone to oxidation, leading to lipid oxidation, as indicated by the increases in TBARs values, particularly at the end of storage.

\subsubsection{Intrinsic Viscosity}

A NMR technique was used in order to determine the changes in flaxseed oil intrinsic viscosity before and after the storage period. The results in Table 1 reveal that flaxseed oil (d0) displayed a relatively lower $\mathrm{T}_{2}$ value $(159.2 \pm 1 \mathrm{~ms})$ compared to that stored during 21 days at $50{ }^{\circ} \mathrm{C}$ in the different pouch formulations. After 21 days of storage, the $\mathrm{T}_{2}$ values of the $\mathrm{FO}$ packaged in gelatin pouches increased to $167.5,168.5,165.5$, and $167.5 \mathrm{~ms}$ for the FG $25^{\circ} \mathrm{C}$, FG $120^{\circ} \mathrm{C}$, FG-Glc $25^{\circ} \mathrm{C}$, and FG-Glc $120{ }^{\circ} \mathrm{C}$ pouches, respectively. For the positive and negative control oils, the $\mathrm{T}_{2}$ values were 163.5 and $160 \mathrm{~ms}$, which are lower than those of packaged FO. Indeed, the $\mathrm{T}_{2}$ parameter corresponds to 
the relaxation time. Generally, if $\mathrm{T}_{2}$ decreases, the sample becomes less viscous and maybe related to the oil degradation [27]. According to the obtained results, we can conclude that the FO intrinsic viscosity decreased, especially for the uncovered oil samples, due to the oxidation process. The $T_{2}$, or relaxation time measured by NRM, represents the time required for the transverse magnetization to fall to approximately $37 \%(1 / \mathrm{e})$ of its initial value. It is directly related to the local viscosity according the Boltzman and Stokes-Einstein laws. Thus, if the oil degradation or oxidation modify (as often) the viscosity of the oil, the $T_{2}$ value will be modified.

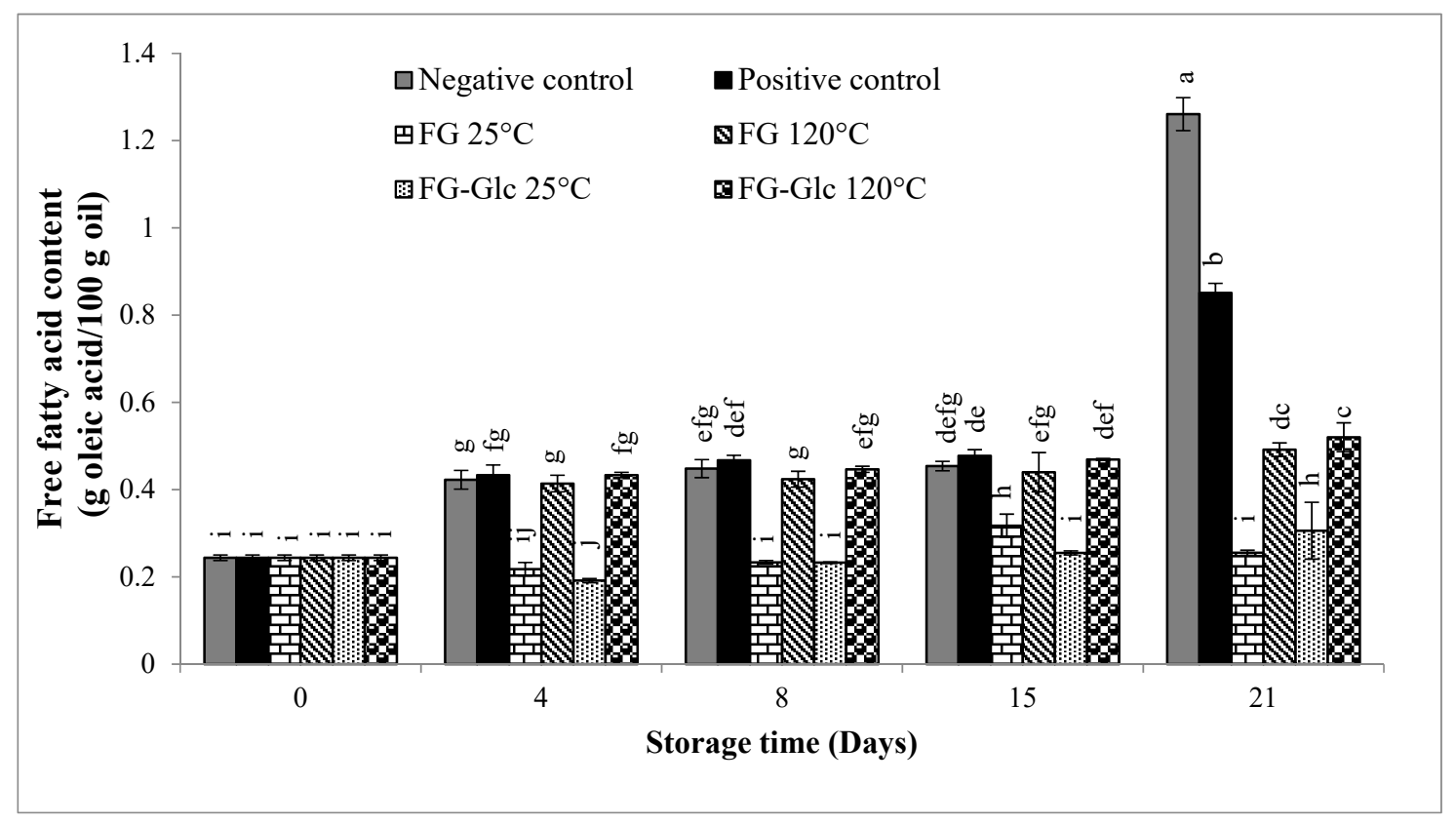

Figure 5. Free fatty acid content of flaxseed oil packaged or not in different gelatin pouches as a function of storage time. Means with different superscripts $(a-j)$ indicate a significant difference $(p<0.05)$.

Table 1. Intrinsic viscosity of flaxseed oil at $\mathrm{d}_{0}$ and after application $\left(\mathrm{d}_{21}\right)$ determined via NMR.

\begin{tabular}{ccc}
\hline \multicolumn{2}{c}{ Oil Samples } & $\mathbf{T}_{\mathbf{2}}(\mathbf{m s})$ \\
\hline \multicolumn{2}{c}{ Flaxseed Oil d } & $159.2 \pm 1.0^{\mathrm{c}}$ \\
\hline & $\mathrm{FG} 25^{\circ} \mathrm{C}$ & $167.5 \pm 0.5^{\mathrm{a}, \mathrm{b}}$ \\
Flaxseed oil d $\mathbf{2 1}_{\mathbf{1}}$ & $\mathrm{FG} 120^{\circ} \mathrm{C}$ & $168.5 \pm 0.5^{\mathrm{a}}$ \\
packaged in & $\mathrm{FG}-G l \mathrm{c} 25^{\circ} \mathrm{C}$ & $165.5 \pm 0.5^{\mathrm{a}, \mathrm{b}}$ \\
& $\mathrm{FG}-\mathrm{Glc} 120^{\circ} \mathrm{C}$ & $167.5 \pm 0.5^{\mathrm{a}, \mathrm{b}}$ \\
& Positive control & $163.5 \pm 1.5^{\mathrm{b}, \mathrm{c}}$ \\
& Negative control & $160.0 \pm 3.0^{\mathrm{c}}$ \\
\hline
\end{tabular}

$\mathrm{a}, \mathrm{b}, \mathrm{c}$ : Values with the same letters are not significantly different a $p=0.05$ level.

\subsubsection{Color}

The changes in FO color were assessed before (day 0) and after (day 21) the storage period, as illustrated in Table 2. FO color parameters were maintained as almost stable after being packaged in gelatin pouches during 21 days under heating conditions $\left(50^{\circ} \mathrm{C}\right)$. However, both the positive and negative controls displayed a notable increase in their a-values and a decrease in their b-values after 21 days of storage at $50{ }^{\circ} \mathrm{C}$. These results prove the variation of the uncovered flaxseed oil color parameters and correlate well with the visual observations, revealing that the oxidation process causes the lightening in the control FO. These findings are in agreement with the observations of Choo et al. [28], who explained that the decrease in color trends (the loss of yellowness) of heated 
flaxseed oils may be due to the reduction of natural carotenoids that are naturally present in flaxseed oil, resulting in their oxidation (bleaching of the carotenoids) or decomposition during heating.

Table 2. Color parameters of flaxseed oil, FG and FG-Glc pouches at the initial time $\left(\mathrm{d}_{0}\right)$ and at 21 days after application $\left(\mathrm{d}_{21}\right)$.

\begin{tabular}{ccccc}
\hline Samples & & L & a & b \\
\hline FO & $\mathrm{d}_{0}$ & $48.44 \pm 0.05^{\mathrm{b}}$ & $-3.71 \pm 0.07^{\mathrm{e}}$ & $14.34 \pm 0.28^{\mathrm{b}}$ \\
FO-FG 25 ${ }^{\circ} \mathbf{C}$ & $\mathrm{d}_{21}$ & $48.44 \pm 0.08^{\mathrm{b}}$ & $-3.42 \pm 0.08^{\mathrm{c}}$ & $15.18 \pm 0.14^{\mathrm{a}}$ \\
FO-FG 120 ${ }^{\circ} \mathbf{C}$ & $\mathrm{d}_{21}$ & $48.29 \pm 0.06^{\mathrm{b}}$ & $-3.42 \pm 0.05^{\mathrm{c}}$ & $15.42 \pm 0.08^{\mathrm{a}}$ \\
FO-FG-Glc 25 ${ }^{\circ} \mathbf{C}$ & $\mathrm{d}_{21}$ & $48.48 \pm 0.02^{\mathrm{b}}$ & $-3.58 \pm 0.02^{\mathrm{d}}$ & $15.58 \pm 0.23^{\mathrm{a}}$ \\
FO-FG-Glc 120 ${ }^{\circ} \mathbf{C}$ & $\mathrm{d}_{21}$ & $48.47 \pm 0.14^{\mathrm{b}}$ & $-3.48 \pm 0.04^{\mathrm{c}, \mathrm{d}}$ & $14.52 \pm 0.08^{\mathrm{b}}$ \\
Positive control & $\mathrm{d}_{21}$ & $49.05 \pm 0.14^{\mathrm{a}}$ & $-0.27 \pm 0.05^{\mathrm{a}}$ & $3.47 \pm 0.42^{\mathrm{c}}$ \\
Negative control & $\mathrm{d}_{21}$ & $49.05 \pm 0.34^{\mathrm{a}}$ & $-0.48 \pm 0.08^{\mathrm{b}}$ & $3.68 \pm 0.39^{\mathrm{c}}$ \\
\hline \multirow{2}{*}{ FG 25 ${ }^{\circ} \mathrm{C}$} & $\mathrm{d}_{0}$ & $89.4 \pm 0.03^{\mathrm{a}}$ & $1.67 \pm 0.04^{\mathrm{a}}$ & $-3.3 \pm 0.10^{\mathrm{a}}$ \\
& $\mathrm{d}_{21}$ & $89.59 \pm 0.17^{\mathrm{a}}$ & $1.64 \pm 0.03^{\mathrm{a}}$ & $-3.16 \pm 0.04^{\mathrm{a}}$ \\
\hline \multirow{2}{*}{ FG 120 ${ }^{\circ} \mathbf{C}$} & $\mathrm{d}_{0}$ & $89.19 \pm 0.02^{\mathrm{a}}$ & $1.14 \pm 0.02^{\mathrm{a}}$ & $-1.87 \pm 0.10^{\mathrm{a}}$ \\
\hline \multirow{2}{*}{ FG-Glc 25 ${ }^{\circ} \mathbf{C}$} & $\mathrm{d}_{21}$ & $89.05 \pm 0.11^{\mathrm{a}}$ & $1.04 \pm 0.03^{\mathrm{a}}$ & $-1.51 \pm 0.04^{\mathrm{a}}$ \\
\hline \multirow{2}{*}{ FG-Glc 120 ${ }^{\circ} \mathbf{C}$} & $\mathrm{d}_{0}$ & $89.46 \pm 0.10^{\mathrm{a}}$ & $1.65 \pm 0.05^{\mathrm{a}}$ & $-3.39 \pm 0.03^{\mathrm{b}}$ \\
& $\mathrm{d}_{21}$ & $88.3 \pm 0.08^{\mathrm{b}}$ & $0.59 \pm 0.01^{\mathrm{b}}$ & $2.72 \pm 0.08^{\mathrm{a}}$ \\
\hline
\end{tabular}

$\mathrm{a}, \mathrm{b}, \overline{c, d, e}$ : Values with the same letters are not significantly different in terms of the flaxseed oil or gelatin pouch color parameters at a $p=0.05$ level.

\subsection{Physicochemical Properties of Gelatin Pouches Related to the Application with Flaxseed Oil}

Firstly, the oxygen transfer rate of the gelatin films was measured at $0 \%$ relative humidity and the obtained values were $0.3 \pm 0.1,0.5 \pm 0.1,0.33 \pm 0.1$ and $0.4 \pm 0.1 \mathrm{~cm}^{3} / \mathrm{m}^{2} \cdot \mathrm{d}$ for FG $25^{\circ} \mathrm{C}, \mathrm{FG} 120^{\circ} \mathrm{C}$, FG-Glc $25^{\circ} \mathrm{C}$, and FG-Glc1 $20^{\circ} \mathrm{C}$, respectively. These results reveal the very low oxygen permeability of gelatin films, with no significant effect from heat treatment nor the Maillard reaction. Therefore, the tested gelatin films can be effectively used as efficient barriers against oxygen transfer. Moreover, the oxygen values are very low compared to that of many edible films, where the values range from to 5 to $2000 \mathrm{~cm}^{3} / \mathrm{m}^{2} \cdot \mathrm{d}$, and, compared to common plastic films, the most efficient (PET/PA/PET three layers) values is about 0.1 , or, for polyolefine films, this ranges from 1000 to $150,000 \mathrm{~cm}^{3} / \mathrm{m}^{2} \cdot \mathrm{d}$ [29-31].

Secondly, the optical properties of the gelatin pouches were investigated by the measurement of their color before (day 0 ) and after (day 21, after being in contact with oil) the storage period. The data in Table 2 display almost the same color parameters ( $\mathrm{L}$, $\mathrm{a}$ and $\mathrm{b}$ ) for the gelatin pouches before and after 21 days of storage at $50{ }^{\circ} \mathrm{C}$, except for the FG-Glc $25^{\circ} \mathrm{C}$ pouches. These pouches showed a slight decrease in their $L$ and a values and a noticeable increase in their $b$ values on the 21st day as compared to the initial day. This variation in color parameters affirms that the storage period (21 days at $50{ }^{\circ} \mathrm{C}$ ) induces a moderate Maillard reaction development in unheated gelatin-glucose-based pouches. Indeed, it is well known that the Maillard reaction occurs rather slowly at $35{ }^{\circ} \mathrm{C}$ but accelerates at temperatures above $55^{\circ} \mathrm{C}$, and most studies dealing with the Maillard reaction have usually been carried out between $55^{\circ} \mathrm{C}$ to $120^{\circ} \mathrm{C}$. Regarding the incubation time, it ranges from as low as $30 \mathrm{~min}$ to as high as $24 \mathrm{~h}$, and even up to several days [32].

These findings were confirmed by the results of UV-visible spectroscopy (Figure 6). As can be seen, only a slight increase in the absorbance spectra (in the range of 250-300 nm) has been revealed for the FG $25^{\circ} \mathrm{C}$ and FG $120^{\circ} \mathrm{C}$ pouches on the 21 st day due to the heating process $\left(50^{\circ} \mathrm{C}\right)$. However, for the FG-Glc $25^{\circ} \mathrm{C}$ pouches, a notable increase of light absorbance was obtained in the range of $250-400 \mathrm{~nm}$. Indeed, this absorbance is specific of Maillard reaction products (MRPs), as previously demonstrated by Etxabide et al. [33]. The development of MRPs in the FG-Glc $25^{\circ} \mathrm{C}$ pouches suggests that these compounds can successfully retard primary lipid oxidation based on their ability to break radical 
chains, breakdown hydrogen peroxide, and scavenge oxygen reactive species [34]. For the FG-Glc $120^{\circ} \mathrm{C}$ pouches, the same UV-visible spectra were obtained before and after 21 days of storage at $50^{\circ} \mathrm{C}$. In addition, the spectra revealed that the FG-Glc $120^{\circ} \mathrm{C}$ pouches exhibit a high protection against UV light in the range of 200-400 nm due to presence of brown MRPs. This protection against UV light suggests the potential preventive effect of FG-Glc $120^{\circ} \mathrm{C}$ pouches on the retardation of product oxidation induced by UV light.
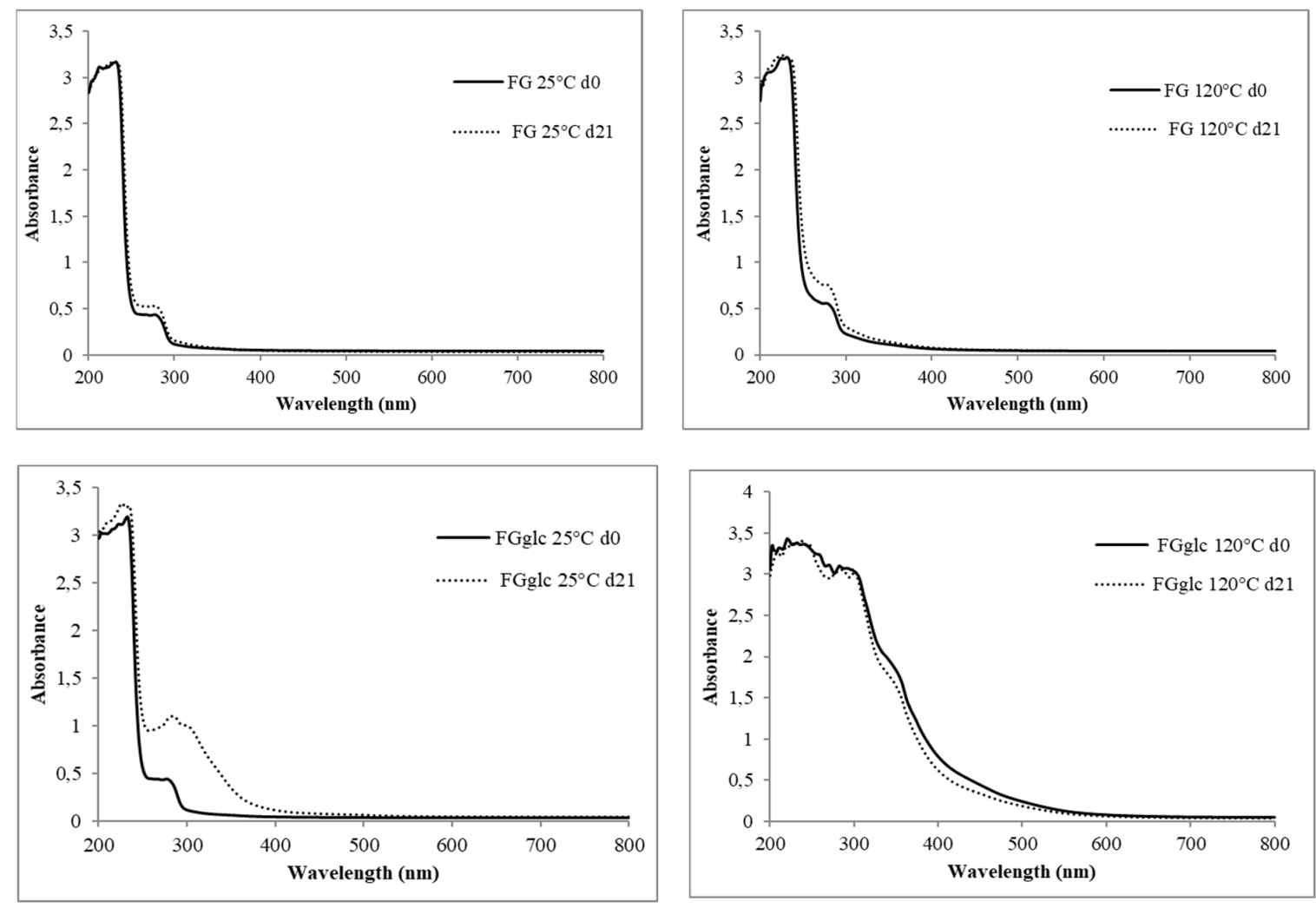

Figure 6. UV-vis spectra of the FG and FG-Glc pouches at day 0 and after application (day 21).

On the other hand, the thermal properties of gelatin pouches before and after the storage period were studied using the differential scanning calorimetry and the glass transition temperature ( $\mathrm{Tg}$ ) was determined from the second heating cycle. As shown in Table 3 and Figure 7, before application, the $\mathrm{Tg}$ value of the unheated glucose-free gelatin pouches was $53.8^{\circ} \mathrm{C}$ and increased to $57.8^{\circ} \mathrm{C}$ after the films were heated at $120^{\circ} \mathrm{C}$ during $24 \mathrm{~h}$. Regarding the gelatin-glucose pouches, their Tg values were $48.4^{\circ} \mathrm{C}$ and $59.8{ }^{\circ} \mathrm{C}$ for the unheated and $120^{\circ} \mathrm{C}$-heated ones, respectively. Further, the thermal properties of the gelatin pouches were investigated for the inner (the pouch part that is in contact with the oil) and outer part of the pouches after the storage period $\left(21\right.$ days at $\left.50{ }^{\circ} \mathrm{C}\right)$. As can be seen, a slight decrease in the $\mathrm{Tg}$ values has been noted for the outer part of the gelatin pouches. However, a notable increase in the Tg values was obtained for gelatin pouch inner parts, probably due to the contact between the flaxseed oil and the pouches. In this context, Taktak et al. [35] noted that the Tg values of European eel oil emulsified gelatin/protein isolate blend films are higher than those of non-emulsified films. Indeed, it has been reported that $\mathrm{Tg}$ increases with the amount of chain stiffness and bonding, along with the crosslinking between chains and the degree of crystallinity [36]. 
Table 3. Glass transition temperature (Tg) of the FG and FG-Glc pouches at the initial time $\left(\mathrm{d}_{0}\right)$ and 21 days after application $\left(\mathrm{d}_{21}\right)$. The inner part consists of the film sample in contact with the oil, whereas the outer part is not in contact with the oil. The average relative error of the data is about $10 \%$.

\begin{tabular}{ccc}
\hline Pouches & & $\mathrm{Tg}\left({ }^{\circ} \mathrm{C}\right)$ \\
\hline \multirow{2}{*}{ FG 25 ${ }^{\circ} \mathrm{C}$} & $\mathrm{d}_{0}$ & 53.8 \\
& $\mathrm{~d}_{21 \text { inner part }}$ & 60.3 \\
& $\mathrm{~d}_{21 \text { outer part }}$ & 51.8 \\
\hline \multirow{2}{*}{ FG 120 ${ }^{\circ} \mathbf{C}$} & $\mathrm{d}_{0}$ & 57.8 \\
& $\mathrm{~d}_{21 \text { inner part }}$ & 66.6 \\
& $\mathrm{~d}_{21 \text { outer part }}$ & 58.4 \\
\hline \multirow{2}{*}{ FG-Glc $25^{\circ} \mathbf{C}$} & $\mathrm{d}_{0}$ & 48.4 \\
& $\mathrm{~d}_{21}$ inner part & 54.1 \\
& $\mathrm{~d}_{21 \text { outer part }}$ & 46.5 \\
\hline \multirow{2}{*}{ FG-G1c $\mathbf{1 2 0}{ }^{\circ} \mathbf{C}$} & $\mathrm{d}_{0}$ & 59.8 \\
& $\mathrm{~d}_{21}$ inner part & 65.7 \\
& $\mathrm{~d}_{21 \text { outer part }}$ & 57.2 \\
\hline
\end{tabular}
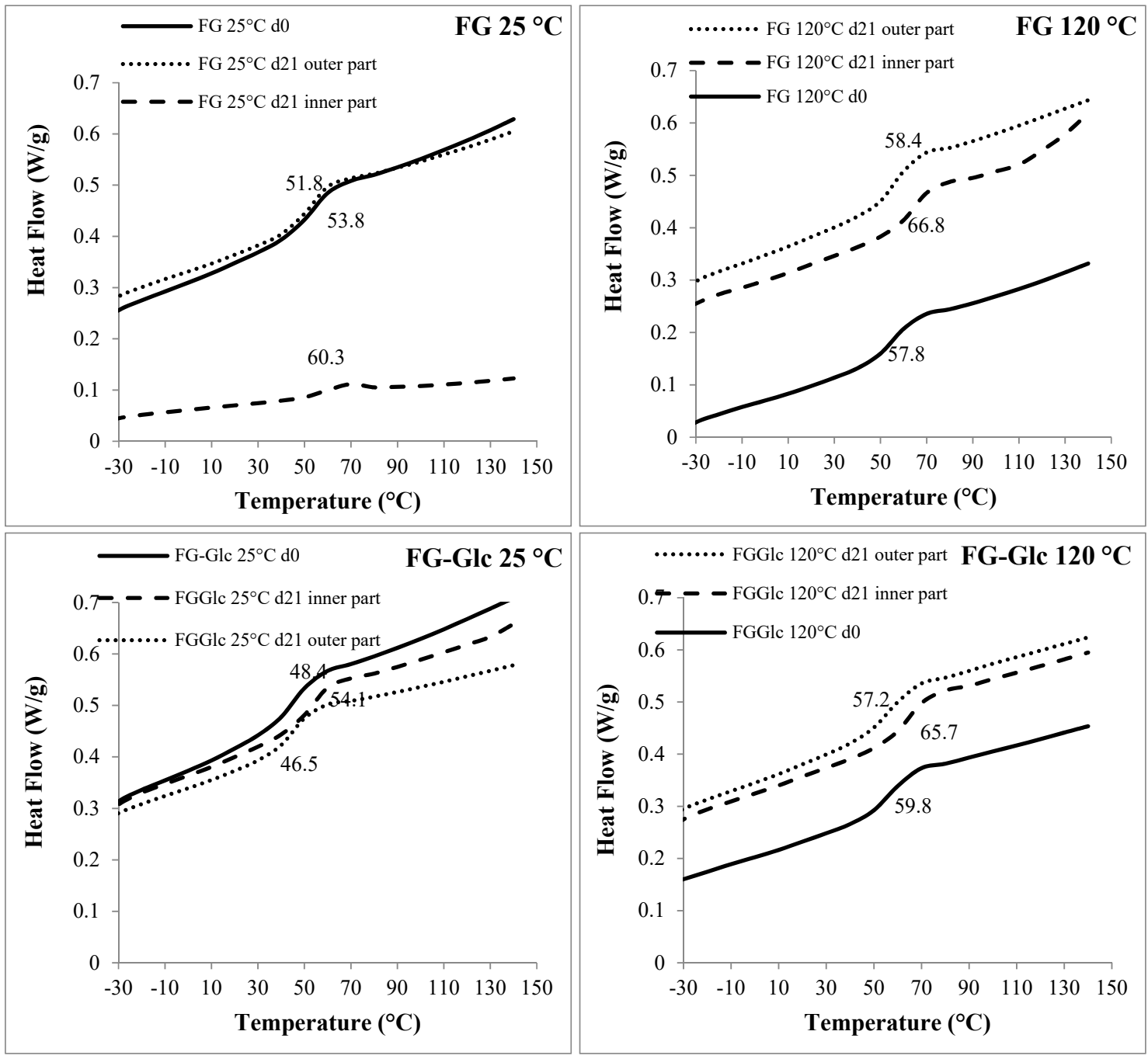

Figure 7. Differential scanning calorimetry (DSC) curves of FG and FG-Glc pouches at $\mathrm{d}_{0}$ and after application $\left(\mathrm{d}_{21}\right)$. 


\section{Conclusions}

A novel formulation of gelatin and gelatin-glucose based pouches has successfully been prepared and investigated here for packaging flaxseed oil and its protection against oxidation under accelerated conditions $\left(50{ }^{\circ} \mathrm{C}, 21\right.$ days). The results found for the peroxide index, TBARs, and FFA assays, monitoring the development of primary and secondary oxidation products, indicate that the different gelatin-based pouch formulations protect flaxseed oil against oxidation, as compared to uncovered oil. Particularly, the non-heated gelatin-glucose pouches showed higher stability for the flaxseed oil, approved by the lower peroxide index, secondary metabolites and free fatty acids values, suggesting therefore a moderate and gradual development of the $\mathrm{MR}$ at $50{ }^{\circ} \mathrm{C}$. Indeed, the protective effect of MR-treated gelatin pouches is due to both their UV and oxygen barrier properties and also due to the bioactive compounds generated by the MR. These interesting findings suggest the potential use of the produced bioactive gelatin pouches as an alternative to synthetic packaging for the protection of sensitive foods against oxidation.

Author Contributions: The individual contribution of H.K. is methodology, experiments, data analyses, validation and original draft preparation and paper writing, M.J. contribution was methodology, data analyses and curation, validation, supervision, professors F.D. and M.N. contributions were mainly focused on supervision, validation of the paper review and editing, project administration and funding acquisition. All authors have read and agreed to the published version of the manuscript.

Funding: Some equipment were financed by the Regional Council of Bourgogne Franche Comte and the Fonds Européen de Développement Régional (FEDER). The cotutelle PhD of Ms Kchaou has been supported by the Utique PHC program (project SeaCoatPack) N 39290YK of Campus France, funded by the Ministries of Education and Research of both France and Tunisia and the French Embassy in Tunisia.

Acknowledgments: The authors gratefully acknowledge the Ministry of Higher Education and Scientific Research in Tunisia for the financial support of this project. The authors wish to thank the colleagues from the PAM-PAPC Laboratory for their precious collaboration and help in some experiments. The authors dedicate a special and friendly thanks to Audrey Bentz, our English teacher colleague who conscientiously revised this manuscript.

Conflicts of Interest: The authors declare no conflict of interest. The funders had no role in the design of the study; in the collection, analyses, or interpretation of data; in the writing of the manuscript, or in the decision to publish the results.

\section{References}

1. Popa, V.M.; Gruia, A.; Raba, D.N.; Dumbrava, D.; Moldovan, C.; Bordean, D.; Mateescu, C. Fatty acids composition and oil characteristics of linseed (Linum usitatissimum L.) from Romania. J. Agroaliment. Process. Technol. 2012, 18, 136-140.

2. Sotomayor-Gerding, D.; Oomah, B.D.; Acevedo, F.; Morales, E.; Bustamante, M.; Shene, C.; Rubilar, M. High carotenoid bioaccessibility through linseed oil nanoemulsions with enhanced physical and oxidative stability. Food Chem. 2016, 199, 463-470. [CrossRef] [PubMed]

3. Huang, J.; Wang, Q.; Li, T.; Xia, N.; Xia, Q. Nanostructured lipid carrier (NLC) as a strategy for encapsulation of quercetin and linseed oil: Preparation and in vitro characterization studies. J. Food Eng. 2017, 215, 1-12. [CrossRef]

4. Piornos, J.A.; Burgos-Díaz, C.; Morales, E.; Rubilar, M.; Acevedo, F. Highly efficient encapsulation of linseed oil into alginate/lupin protein beads: Optimization of the emulsion formulation. Food Hydrocolloid 2017, 63, 139-148. [CrossRef]

5. Gray, J.I. Measurement of lipid oxidation: A review. J. Am. Oil Chem. Soc. 1978, 55, 539-546. [CrossRef]

6. Sai-Ut, S.; Benjakul, S.; Rawdkuen, S. Retardation of lipid oxidation using gelatin film incorporated with longan seed extract compared with BHT. J. Food Sci. Technol. 2015, 52, 5842-5849. [CrossRef]

7. Guillén, M.D.; Ruiz, A. Oxidation process of oils with high content of linoleic acyl groups and formation of toxic hydroperoxy- and hydroxyalkenals. A study by ${ }^{1} \mathrm{H}$ nuclear magnetic resonance. J. Sci. Food Agric. 2005, 85, 2413-2420. [CrossRef]

8. Ksouda, G.; Hajji, M.; Sellimi, S.; Merlier, F.; Falcimaigne-Cordin, A.; Nasri, M.; Thomasset, B. A systematic comparison of 25 Tunisian plant species based on oil and phenolic contents, fatty acid composition and antioxidant activity. Ind. Crop. Prod. 2018, 123, 768-778. [CrossRef] 
9. Kahl, R.; Kappus, H. Toxicology of the synthetic antioxidants BHA and BHT in comparison with the natural antioxidant vitamin E. Z. Lebensm. Unters. Forsch. 1993, 196, 329-338. [CrossRef]

10. Yu, R.; Mandlekar, S.; Tony Kong, A.N. Molecular mechanisms of butylated hydroxylanisole-induced toxicity: Induction of apoptosis through direct release of cytochrome c. Mol. Pharmacol. 2000, 58, 431-437. [CrossRef]

11. Śpitalniak-Bajerska, K.; Szumny, A.; Kucharska, A.Z.; Kupczyński, R. Effect of natural antioxidants on the stability of linseed oil and fish stored under anaerobic conditions. J. Chem. 2018. [CrossRef]

12. Varas Condori, M.A.; Pascual Chagman, G.J.; Barriga-Sanchez, M.; Villegas Vilchez, L.F.; Ursetta, S.; Guevara Perez, A.; Hidalgo, A. Effect of tomato (Solanum lycopersicum L.) lycopene-rich extract on the kinetics of rancidity and shelf-life of linseed (Linum usitatissimum L.) oil. Food Chem. 2020, 302, 125327. [CrossRef]

13. Taktak, W.; Nasri, R.; Lopez-Rubio, A.; Hamdi, M.; Gomez-Mascaraque, L.G.; Ben Amor, N.; Kabadou, A.; Li, S.; Nasri, M.; Chaâbouni-Karra, M. Improved antioxidant activity and oxidative stability of spray dried European eel (Anguilla anguilla) oil microcapsules: Effect of emulsification process and eel protein isolate concentration. Mater. Sci. Eng. C 2019, 104, 109867. [CrossRef]

14. Nilsuwan, K.; Benjakul, S.; Prodpran, T.; de la Caba, K. Fish gelatin monolayer and bilayer films incorporated with epigallocatechin gallate: Properties and their use as pouches for storage of chicken skin oil. Food Hydrocoll. 2019, 89, 783-791. [CrossRef]

15. Kchaou, H.; Benbettaïeb, N.; Jridi, M.; Nasri, M.; Debeaufort, F. Influence of Maillard reaction and temperature on functional, structure and bioactive properties of fish gelatin films. Food Hydrocoll. 2019, 97, 105196. [CrossRef]

16. Kchaou, H.; Benbettaïeb, N.; Jridi, M.; Abdelhedi, O.; Karbowiak, T.; Brachais, C.-H.; Léonard, M.-L.; Debeaufort, F.; Nasri, M. Enhancement of structural, functional and antioxidant properties of fish gelatin films using Maillard reactions. Food Hydrocoll. 2018, 83, 326-339. [CrossRef]

17. Uluata, S.; McClements, D.J.; Decker, E.A. How the multiple antioxidant properties of ascorbic acid affect lipid oxidation in oil-in-water emulsions. J. Agric. Food Chem. 2015, 63, 1819-1824. [CrossRef]

18. Qiu, C.; Zhao, M.; Decker, E.A.; McClements, D.J. Influence of protein type on oxidation and digestibility of fish oil-in-water emulsions: Gliadin, caseinate, and whey protein. Food Chem. 2015, 175, 249-257. [CrossRef]

19. Boscou, D. Olive oil: Chemistry and technology. Champaign Illinois. Am. Oil Chem. Soc. 1996, 69, 552-556.

20. Takeungwongtrakul, S.; Benjakul, S.; H-kittikun, A. Lipids from cephalothorax and hepatopancreas of Pacific white shrimp (Litopenaeus vannamei): Compositions and deterioration as affected by iced storage. Food Chem. 2012, 134, 2066-2074. [CrossRef]

21. Shahidi, F.; Zhong, Y. Lipid oxidation and improving the oxidative stability. Chem. Soc. Rev. 2010, 39, 4067-4079. [CrossRef] [PubMed]

22. Stoll, L.; Da Silva, A.M.; Iahnke AO, E.S.; Haas Costa, T.M.; Flores, S.H.; Rios, A.D.O. Active biodegradable film with encapsulated anthocyanins: Effect on the quality attributes of extra-virgin olive oil during storage. J. Food Process. Preserv. 2017, 41, 13218-13225. [CrossRef]

23. Cho, S.Y.; Lee, S.Y.; Rhee, C. Edible oxygen barrier bilayer film pouches from corn zein and soy protein isolate for olive oil packaging. Lwt Food Sci. Technol. 2010, 43, 1234-1239. [CrossRef]

24. Nawar, W.W. Lipids. In Food Chemistry; Fennema, O.R., Ed.; Marcel Dekker, Inc.: New York, NY, USA, 1996; pp. 225-319.

25. Wolff, J.-P. Manuel d'analyse des corps gras, Edition; Azoulay: Paris, France, 1968.

26. Pacheco-Aguilar, R.; Lugo-Sánchez, M.; Robles-Burgueño, M. Postmortem biochemical and functional characteristic of Monterey sardine muscle stored at $0{ }^{\circ} \mathrm{C}$. J. Food Sci. 2000, 65, 40-47. [CrossRef]

27. Roos, Y.H. Relaxations, Glass Transition and Engineering Properties of Food Solids. In Advances in Food Process Engineering Research and Applications; Springer: Berlin, Germany, 2013.

28. Choo, W.S.; Birch, E.J.; Dufour, J.P. Physicochemical and stability characteristics of flaxseed oils during pan-heating. J. Am. Oil Chem. Soc. 2007, 84, 735-740. [CrossRef]

29. Miller, K.S.; Krochta, J.M. Oxygen and aroma barrier properties of edible films: A review. Trends Food Sci. Technol. 1997, 8, 228-237. [CrossRef]

30. Ayranci, E.; Tunc, S. A method for the measurement of the oxygen permeability and the development of edible films to reduce the rate of oxidative reactions in fresh foods. Food Chem. 2003, 80, 423-431. [CrossRef]

31. Cerqueira MA, P.R.; Pereira RN, C.; da Silva Ramos, O.L.; Teixeira JA, C.; Vicente, A.A. Edible Food Packaging: Materials and Processing Technologies; CRC Press: Boca Raton, FL, USA, 2016. 
32. Lee, Y.-Y.; Tang, T.-K.; Phuah, E.-T.; Alitheen NB, M.; Tan, C.-P.; Lai, O.-M. New functionalities of Maillard reaction products as emulsifiers and encapsulating agents, and the processing parameters: A brief review. J. Sci. Food Agric. 2017, 97, 1379-1385. [CrossRef]

33. Etxabide, A.; Uranga, J.; Guerrero, P.; de la Caba, K. Improvement of barrier properties of fish gelatin films promoted by gelatin glycation with lactose at high temperatures. Lwt Food Sci. Technol. 2015, 63, 315-321. [CrossRef]

34. Nooshkam, M.; Madadlou, A. Maillard conjugation of lactulose with potentially bioactive peptides. Food Chem. 2016, 192, 831-836. [CrossRef]

35. Taktak, W.; Kchaou, H.; Hamdi, M.; Li, S.; Nasri, M.; Chaâbouni-Karra, M.; Nasri, R. Design of bioinspired emulsified composite European Eel gelatin and protein isolate-based food packaging film: Thermal, microstructural, mechanical, and biological features. Coatings 2020, 10, 26. [CrossRef]

36. Rogers, C.E. Permeation of gases and vapors in polymers. In Polymer Permeability; Comyn, J., Ed.; Elsevier Applied Science: London, UK, 1985; pp. 11-73.

(C) 2020 by the authors. Licensee MDPI, Basel, Switzerland. This article is an open access article distributed under the terms and conditions of the Creative Commons Attribution (CC BY) license (http://creativecommons.org/licenses/by/4.0/). 